\title{
Research on the Symbolic Meaning of National Costumes - Take Cheongsam and Kimono as an example
}

\author{
Yingxin Qi ${ }^{1}$ \\ ${ }^{1}$ College of Tourism of Northwest Normal University, Lanzhou Gansu, 730070, China
}

\begin{abstract}
Keywords: Ethnic Clothing, Symbolic meaning, Cheongsam, Kimono,
\end{abstract}
\begin{abstract}
As an important manifestation of social civilization, clothing has long been not just clothing itself, but a socialized political, economic and cultural carrier that has been materialized, and is a materialized expression of specific cultural values. In particular, in addition to embodying the national aesthetic consciousness, cultural changes, and national wisdom, national costumes can also display national character. Based on Goffman's theory of drama, this paper analyzes the symbolic meaning of national costumes and compares the symbolic meanings of the two national costumes.
\end{abstract}

\section{Introduction}

Clothing is closely linked to the history of civilization for thousands of years. Different countries have different values, religious beliefs, customs and habits due to different geographical, cultural backgrounds and social forms which affect people's choice of clothing, and finally form their own different traditional costumes. With the development of economic globalization and global integration, the differences between ethnic groups are shrinking, and the items belonging to national memory are gradually disappearing. Therefore, national costumes have increasingly become the symbol and representative of the nation.

\section{Goffman's Drama Theory and Symbolic Performance of Costumes}

Goffman was a famous sociologist in the 1960s and one of the main representatives of symbolic interaction theory. In his book "Self-presentation in Daily Life", Goffman first introduced the theory of drama into the field of sociology. Social life is likened to drama performance, which constructs the theory of drama, mainly discussing the interaction between people in daily life ${ }^{[1]}$. Drama theory uses performances and metaphors to explain the interaction of people in daily life. It holds that society is a stage, and all members of society are actors who play different roles on this stage and are all in social interaction. "Perform self, shape your image and better achieve your goals"[2].

Goffman believes that the stage can be divided into "front" and "backstage". Therefore, in the interpersonal interaction, people also divide social life into "front" and "backstage" in order to carry out "performance" activities. The front desk is a kind of"collective appearance"and "selfindependence" facts, and thus has an institutionalized stability, which in turn restricts the role that actors play. The backstage is a concept opposite to the "foreground". It is a place that is isolated from the performance venue and cannot be accessed by the audience. It is at the end of the performance front.

In Goffman's view, in order to maintain effective social interaction, and a definition of the situation in line with social expectations, people are always acting. In the social arena, everyone is both an actor and an audience. Whether people believe in their performances, he always tries to create an image that the audience believes ${ }^{[3]}$. In the process of interaction, both parties should interpret the symbols and then take corresponding actions. Clothing also has symbolic meaning. For example, when wearing sportswear, the destination may be the gym. In order to perform better, people will use a lot of props. Costumes are one of the props. Through the costumes, the performers can enhance their self-confidence and achieve better performance. The definition behind the scenes of women wearing national costumes should reflect the unique national character and development history of the nation different from other nations in the category of common sense of society. The 
performance of an individual in a specific time, showing a certain situation for the audience, with the help of standard, regular settings and props, Goffman called this area of the performance "front" ${ }^{[4]}$. The signal that each national costume transfer to the audience at the front desk is different. In the interaction between people, the meaning of people's understanding through clothing is different. In this article, the foreground is defined as the performance of women in traditional costumes on the stage. The performance at this time is to ignore the personality.

\section{The evolution of national costumes}

Cheongsam which Chinese pinyin is qipao here refers to Chinese traditional Cheongsam for women. It is regarded as the representative of Chinese costume culture. It is a typical national costume with typical internal and external harmony. It is a combination of Chinese and Han culture and is the crystallization of Chinese national costume culture. Kimono crystalized Japanese wisdom is a precious cultural heritage that Japanese people are proud of. Its evolution and development have reflected efforts of the Japanese people of the past generations. Finally Kimono has developed into traditional costumes that best conform to the characteristics and character of the Japanese.

\subsection{Cheongsam}

In the narrow sense, Cheongsam can be understood as the style of clothing that began in the 1920s and popular in the 1930s and 1940s. It was a combination of vests, Chinese traditional cottonpadded coat (pinyin:ao) and the so-called "civilized new clothes". In a broad sense, Cheongsam has experienced several stages such as Han Chinese robe, traditional Manchu robe, folk Cheongsam, and classic Cheongsam. From the name part, there is a constant relationship with the flag robes. The shape of the two does have some common features. Such as the one-piece robes, the buckles, the piping, etc, the daily robes of the Manchu women in the Qing Dynasty(1636AD-1912AD) are like this. At the end of the Qing Dynasty and the beginning of the Republic of China, the Han women's dresses were mostly the upper coat with the lower pants or skirt, the so-called "two-piece dress". The general trend is more and more succinct, the decoration from the large inlay to the simple piping, the upper coat is more suitable for body, the length of the garment to the bottom of the hip or knee, left and right open, the length of the skirt can be lowered to the instep. In the 1920s, there were women wearing robes in Shanghai. At first, there were only a few women, and women who were finally full of streets wore Cheongsam. This kind of robes is similar to the Cheongsam of the Qing Dynasty. It is called "Qipao"[5]. Zhang Ailing pointed out in the dress code in "A Chronicle of Changing Clothes": The appearance of Cheongsam is related to the awakening of female consciousness Since the beginning of the Republic of China, women in Shanghai have been influenced by Western culture, pursuing equality and progress, and their awareness of affirmation has increased while women's consciousness has begun to awaken. At the beginning of the Cheongsam, it still remains a considerable traditional taste, but soon it is separated from the old tradition, becoming more fashionable and more modern. In the 1930s, Cheongsam entered the golden age, from the wife of the president to the civilian women, all dressed in Cheongsam. Since the 1940s, in order to achieve the western-style fit, the cutting process has been improved and the way of wearing has changed. At this time, the Cheongsam became more concise, and the decoration could be avoided. Therefore, the Cheongsam of the 1940s was simple and modern, but it was also the most feminine ${ }^{[6]}$.

\subsection{Kimono}

The origin of the kimono dates back to the third century AD. According to"Records of Wei in the Period of Three Kingdom: Biography of wajin", it is recorded in the book: "Use a piece of cloth, wear a hole in the middle, and cross the head, no need to tailor it". This kimono was first called "kantoyi", it was women's wear. "Kantoyi" is to dig a hole in the cloth, set it up from the head and then tie the cloth under the two shackles with a belt, and then wear a skirt similar to the skirt, 
original and practical. In the jyomon period and the yayoi era, there were two styles of clothing in Japan. One is a pullover t-shirt; the other is a pair of squats, the sill is left-handed, the collar is at the waist, the two are equidistantly fastened with a string, the sleeve is a sleeve, and the length is above the knee.

The Nara era was the heyday of Sino-Japanese exchanges. Japan sent missions to China many times. Therefore, the "Tangstyle Culture" in Japan's Nara era prevailed. At this time, the kimono was also deeply influenced by the clothing of the Tang Dynasty(618AD-907AD). The whole piece of clothing had neither a buckle nor an ankle strap. Instead, it covered the left ankle on the right ankle on the chest, and then tied it with a belt or a Kimono belt at the waist. The heian period is a period in which the "national style culture" that displays Japan's unique culture prevails. At this time, the Kimono gradually got rid of the external influence, developed the luxury and exquisiteness with the unique charm of Japan, the color is more diverse, and the sleeves become more spacious. The well-known "jyunihitoe" are costumes that appeared in the heian era and were loved by aristocratic women. In the Kamakura period, the "Busi culture" appeared, pursuing lean and simple. This feature is also reflected in the Kimono ${ }^{[7]}$. From the Kamakura period to the Muromachi era, the Kimono has returned to simplicity, focusing on practicality. At the same time, "kosode" have become popular. In addition, ancient Japan has a family pattern by family name, and printed on the clothes, which is also the main feature of Japanese Kimono at this time. The edo period is an era in which the "machi culture" prevails, showing the momentum of the spread of culture to the entire nation. Previously, the customs and habits that were only popular among the nobility and the warriors began to gradually become civilian. At this time, the Kimono began to become civilian, and the shape of the small sleeves became modern, and the knot became popular. The development of Kimono in the edo period reached its peak, and although there were minor changes, the basic pattern has been set. In the Meiji era, the Kimono in the modern sense was finalized, and it has not changed much since. Most of the Kimono we see today continue the clothing characteristics of the edo period.

\section{Comparison of performance differences between Cheongsam and Kimono}

\subsection{The "exposion" of Cheongsam and "hidden" of Kimomo}

Cheongsam reveals the unique body curve of women and shows the return and care of costumes to people, which makes the feudal shackles that have been tied to Chinese women for thousands of years completely broken. The significance of the feminine curvacem embodied in Cheongsam at the front desk is the suppression of Chinese women and the liberation of restraints. During the feudal rule of China for thousands of years, women's social status and family status were extremely low, and their feet were bound and even could not go out. Therefore, the Cheongsam's exposion not only liberated Chinese women from heavy clothing, but also liberated from the moral bondage of thousands of years. Women's nature was released, awareness of affirmation gradually increased, and female consciousness began to awaken.

Different from the Cheongsam, the Kimono is hidden. Although the social status of ancient Japanese women was not high, in Japan, women were not subject to any restrictions, and women held the economic power of the family. Although women must rely on men to survive, compared with women in ancient China, they had more freedom. Although there was no right to speak in political activities, in some aspects of family affairs, women had the right to decide. Therefore, the desire of Japanese women to break free from bondage is not very strong. Therefore, in the development and evolution of kimono after thousands of years, women's awareness of affirmation is not particularly strong, so the kimono does not highlight the curvaceous beauty of women. Firstly Kimono is bound to hide the physical deficiency of Japanese women. Based on the human body structure, the proportion of Japanese women's body is shorter, and the Kimono just hides this deficiency. The belt tied at the waist will elongated the look of legs, so that the body proportions tend to coordinate. Then Kimono is to hide the inner world. The famous anthropologist Ruth 
Benedict used a lot of turning sentences when analyzing the Japanese character in the book "Chrysanthemum and Knife", indicating that there are many contradictions and oppositions in the Japanese character. A major feature of Japanese expression is "aimaigo", that is, the Japanese do not be straightforward when expressing their subjective will, they will choose to use a very sloppy way to avoid embarrassing other people.

It can be seen that the Yamato people's ability to learn and accept foreign culture is stronger and deeper, and gradually combines the absorbed foreign culture with traditional culture to form a new and distinctive national culture. Internalization has become its own culture, which is worth learning and learning from.

\subsection{Traditional inheritance and abandonment}

National costume styles and accessories have been fixed after a long period of development and evolution. One of the main features of the kimono is the belt tied around the waist. There is no button on the whole body. Only the strap is attached to the waist to fix the kimono. This is the difference between many costumes and the beginning of the development of the kimono. When wearing kimonos, you must wear geta, tabi, motodori. These accessories and habits have been passed down for hundreds of years. Today, they are still a must-have for the Kimono. Only after matching these accessories, the Kimono can completely showing the tenderness and beauty of women. The final shape of the Cheongsam is only reflected in the clothing. As for the accessories and the headwear, the only accessories that continue to be the buckles and piping on the cheongsam. Modern women can wear their Cheongsams to match their personal preferences with modern accessories.

\subsection{Nationality}

\subsubsection{Absorption and internalization of foreign culture}

Most of the traditional culture in Japan come from China, because before the Meiji Restoration, Japan had always used China as a learning object to learn advanced culture from China. The exchanges of Chinese and Japanese culture have a long history. In the Sui Dynasty(581AD-618AD), Japan began to send messengers to China, and reached its peak in the Tang Dynasty. At that time, Chinese characters were introduced to Japan, and the Japanese created their own characters based on Chinese characters - Kana. At that time, the Japanese also built a city Nara taking after the capital of Chang'an. In the late of Bakuhu, after Japan's national gate was opened by Western developed countries such as Britain and the United States, Japan began to turn to the West. A large number of gairaigo in Japanese language today are the expression of learning Western languages. The kimono has gradually become a festival costume, and daily clothing has been replaced by a suit. Japan can rise rapidly from the heavy losses in World War II, and it all reflects the learning spirit of the Japanese nation.

As an ancient civilization with a history of more than 5,000 years, China had been a world power before the Ming(1368AD-1644AD) and Qing Dynasties with advanced culture and technology. At that time, China did not feel any need to learn form other countries. Until the early Ming Dynasty, China was still a big country with all the countries coming to visit and learn. Therefore, such Chinese people had their own arrogance and confidence. Until modern times, the prelude to learning foreign culture in China was gradually opened, and this kind of learning was forced.

It can be seen that the Yamato people's ability to learn and accept foreign cultures is stronger and deeper, and internalizes them into their own culture, which is worth our learning.

\subsubsection{Love nature}

Due to the special location of Japan, the natural scenery of Japan is very beautiful. And Japan has 
four distinct seasons, each with its own characteristics in Japan. For example, April is the season when cherry blossoms are open. Once this season, the Japanese will go to enjoy the flowers. Everyone sits around the cherry trees, sings and dances, expresses their love for nature, and many festivals are inseparable from nature. The pattern and color of the kimono are closer to nature. In addition to the kimonos that attend the funeral, other kinds of kimonos will have plants or animal patterns. Cheongsam is slightly different, you can not decorate, plain cheongsam can still show female beauty. Even the decorative patterns are mostly auspicious symbols. Most of them use flower-shaped, colorful flowers or animated birds. These patterns are hidden in the decoration. For example, the phoenix and the peony are rich and auspicious, and the pine tree and the crane are like the longevity. As everyone knows, the Japanese have to report. The good natural environment gives the Japanese a lot of favors, and all Japanese have to repay their nature. Therefore, the Japanese love of nature contains the gratitude of nature.

\section{Summary}

National costumes, as props for performances, have different symbolic meanings than ordinary costumes. National costumes have been endowed with the commonality of the nation in the long history of their development.This paper uses Goffman's theory of drama to analyze the symbolic meaning of national costumes and compare the symbolic meanings of two different national costumes.The full text has many shortcomings, which will be improved and strengthened in future research.

\section{References}

[1]-[2] Zhou Mei. Li Guiping. The Theory of Drama in Interpersonal Interaction-Interpretation of Self-presentation in Daily Life [J]. Economic Research Guide, 2010, 12, 210-210.

[3] Yu Hai. History of Western Social Thoughts [M]. Fudan University Press, 3rd edition, October 2011, 263-265.

[4] Hou Yusheng. Western sociology theory course [M]. Nankai University Press, 3rd edition, July 2010, 259-263.

[5]-[6]Yuan Xuanping. Folk cheongsam and Shanghai culture [J]. Decoration, 2016, 04, 024-026.

[7] Pan Wei, Yin Shengnan. Research on the quality of traditional Chinese and Japanese clothing [J]. Journal of Jilin Overseas Chinese Language and Literature University, 2009, 1, 33-37. 